\title{
Do exercise-based prevention programmes reduce non-contact musculoskeletal injuries in football (soccer)? A systematic review and meta-analysis with 13355 athletes and more than 1 million exposure hours
}

\author{
Italo Ribeiro Lemes (ㄷ), ${ }^{1}$ Rafael Zambelli Pinto (ㄷ) , 1,2 Vitor N Lage, ${ }^{2}$ \\ Bárbara A B Roch, ${ }^{2}$ Evert Verhagen (1) ${ }^{3}$ Caroline Bolling, ${ }^{3}$ Cecilia Ferreira Aquino, ${ }^{4,5}$ \\ Sérgio T Fonseca (i) , ${ }^{1,2}$ Thales R Souza (1) ${ }^{1,2}$
}

\begin{abstract}
- Additional supplemental material is published online only. To view, please visit the journal online (http://dx.doi. org/10.1136/bjsports-2020 103683)
\end{abstract}

${ }^{1}$ Graduate Program in Rehabilitation Sciences, Universidade Federal de Minas Gerais (UFMG), Belo Horizonte, MG, Brazil

${ }^{2}$ Department of Physical Therapy, Universidade Federal de Minas Gerais (UFMG), Belo Horizonte, MG, Brazil

${ }^{3}$ Amsterdam Collaboration on Health and Safety in Sports \& Department of Public and Occupational Health, VU University Medical Center, Amsterdam, The Netherlands ${ }^{4}$ Department of Physical Therapy, Universidade José do Rosário Vellano, Divinópolis, MG, Brazil

${ }^{5}$ Department of Physical

Therapy, Universidade do Estado de Minas Gerais (UEMG)، Divinópolis, MG, Brazil

\section{Correspondence to}

Thales R Souza, Department of Physical Therapy, Universidade Federal de Minas Gerais (UFMG), Belo Horizonte 31270 901, MG, Brazil;

thalesrs@ufmg.br

Accepted 4 May 2021 Published Online First 17 May 2021

Check for updates

(C) Author(s) (or their employer(s)) 2021. No commercial re-use. See rights and permissions. Published by BMJ.

To cite: Lemes IR

Pinto RZ, Lage VN,

et al. Br J Sports Med

2021:55:1170-1178.

\section{ABSTRACT}

Objective The aim of this systematic review was to investigate the effect of exercise-based programmes in the prevention of non-contact musculoskeletal injuries among football players in comparison to a control group. Design Systematic review and meta-analysis of randomised controlled trials.

Data sources MEDLINE, EMBASE, CENTRAL, CINAHL, PEDro and SPORTDiscus databases were searched from the earliest record to January 2021.

Eligibility criteria Studies were eligible if they (1) included football players aged 13 years or older, (2) used exercise-based programmes as intervention, (3) presented the number of non-contact musculoskeletal injuries (ie, defined as any acute sudden onset musculoskeletal injury that occurred without physical contact) and exposure hours for each group, and (4) had a control group (eg, usual training, minimal intervention, education). All types of exercise-based prevention programmes were eligible for inclusion. Risk of bias for each included study and overall quality of evidence for the meta-analysis were assessed.

Results Ten original randomised controlled trials with 13355 football players and 1062711 hours of exposure were selected. Pooled injury risk ratio showed very low-quality evidence that exercise-based prevention programmes reduced the risk of non-contact musculoskeletal injuries by $23 \%(0.77(95 \% \mathrm{Cl} 0.61$ to 0.97)) compared with a control group.

Conclusion Exercise-based prevention programmes may reduce the risk of non-contact musculoskeletal injuries by $23 \%$ among football players. Future highquality trials are still needed to clarify the role of exercise-based programmes in preventing non-contact musculoskeletal injuries among football players.

PROSPERO registration number CRD42020173017.

\section{INTRODUCTION}

Football (soccer) is one of the most popular sports worldwide. It is estimated that more than 250 million men and women, from children to elderly, with different socioeconomic backgrounds and levels of expertise, play football. ${ }^{12}$ Besides the well-known health benefits of sports participation, ${ }^{3-6}$ there is an increased risk of musculoskeletal injuries. Injury rate among professional and amateur players may vary. Previous research has shown that injury rates among amateurs and professionals are 9.6 and 8.1 per 1000 hours of exposure, respectively, ${ }^{78}$ and up to half of these injuries are muscle injuries. ${ }^{9}$

Although football is a sport with frequent physical contact, occurrence of non-contact musculoskeletal injuries, such as hamstring strain and anterior cruciate ligament (ACL) rupture, is common. ${ }^{10}$ There is evidence showing that more than $90 \%$ of all muscle injuries and 51\%-64\% of joint/ligament injuries (ie, ACL) in football occur in non-contact situations. ${ }^{11-13}$ Lower limb injuries are the most common type of injury in football and most of these $(66 \%)$ are non-contact injuries and, therefore, preventable. ${ }^{14}$ Recovery from non-contact injury depends on the type and severity of injury but often requires athletes to take time off from sports. For instance, an acute hamstring strain (grade I or II) may take up to 8 weeks of rehabilitation, ${ }^{15}$ while time loss following an ACL injury is $\sim 7.5$ months. ${ }^{12}$

Sport injuries can affect the athlete's physical and mental health and, consequently, impact team's performance. ${ }^{16-19}$ Professional teams lose approximately $£ 45$ million ( US\$55 million) per season due to injuries from 2012 to $2017 .^{20}$ To reduce absence from training and competition, interventions to reduce injuries among football players have been developed. ${ }^{21} 22$ One of the available intervention programmes for football players is the general (ie, targeting multiple body parts) exercise-based programme FIFA $11+.^{23}$ This general programme has been shown to reduce overall injury rate by $39 \%$. $^{22}$ Focused programmes, comprised of exercises targeting a specific muscle group (eg, the Nordic Hamstring Exercise (NHE)), may provide extra protection for the targeted tissue ${ }^{21}$ as it is shown to reduce the risk of hamstring injury by $46 \%$ among amateur football players. ${ }^{24}$ Despite the burden of non-contact musculoskeletal injuries to athletes and their teams, the efficacy of focused and general exercise-based programmes to prevent noncontact musculoskeletal injuries and the overall incidence rate of such injuries remains unclear.

Previous systematic reviews investigating exercisebased programmes to prevent injuries in football 
players combined data from all types of injuries and/or interventions. ${ }^{225-28}$ Given that the injury profile and incidence vary across teams and leagues, ${ }^{2930}$ it would be informative to estimate the efficacy of exercise-based programmes, including focused and general exercise programmes, specifically for preventing non-contact musculoskeletal injuries. In addition, informing injury incidence of non-contact injuries would contribute to the development of future interventions. This information may be incorporated in pre-season and during-season training plans.

To the best of our knowledge, there is no systematic review assessing the efficacy of exercise-based programmes in the prevention of non-contact musculoskeletal injuries among football players. The primary aim of this systematic review and metaanalysis was to evaluate the effects of exercise-based programmes in the prevention of non-contact musculoskeletal injuries among football players in comparison with a control group. In addition, we aimed to (1) investigate whether there are differences in the estimates between focused and general exercises on the prevention of specific non-contact injuries, and (2) report the injury incidence of non-contact injuries using data from control groups.

\section{METHODS}

The Preferred Reporting Items for Systematic Reviews and Meta-Analysis (PRISMA) guidelines were followed for reporting of this review. ${ }^{31}$ The protocol for this review was prospectively registered in the PROSPERO database (CRD42020173017). ${ }^{32}$

\section{Search strategy and inclusion criteria}

The search for relevant studies was performed in six databases (MEDLINE, EMBASE, CENTRAL, CINAHL, PEDro and SPORTDiscus) from the earliest record to 10 March 2020 and updated on 14 January 2021. Clinical trial registries, such as clinicaltrials.gov, the International Standard Randomised Controlled Trial Number Register (IRSCTN) and the Australian-New Zealand Clinical Trials Registry (ANZCTR), were also searched for potential ongoing or unpublished trials. The search strategy used a combination of terms related to football, soccer, prevention and randomised controlled trial (online supplemental table 1). The reference list of previous systematic reviews in the topic was checked to find potential studies that could also be used in this review. There was no restriction regarding language of publication.

Only randomised controlled trials investigating the efficacy of exercise-based programmes compared with a control group for preventing non-contact musculoskeletal injuries in football players were included. An exercise-based prevention programme was defined as any exercise therapy that was performed in order to develop or improve function, skills or physical fitness. Control group was defined as usual training/warm-up, minimal intervention, education or not exposed to the intervention. Non-contact musculoskeletal injuries were the primary outcome in this review and was defined as any acute sudden onset musculoskeletal injury that occurred without physical contact by another player or object on the field. ${ }^{33}$ Studies were eligible if they (1) included football players aged 13 years or older, (2) used exercisebased programmes as intervention, (3) presented number of non-contact injuries and exposure hours for each group, and (4) had a control group. All types of exercise-based prevention programmes were eligible for inclusion. Studies reporting overall injuries were included if it was possible to extract the data specific to non-contact injuries. When information about the injuries was unclear, we contacted the authors via email to confirm or clarify the number of non-contact injuries. A total of three attempts to contact the authors were made. If missing or unclear data could not be provided by the authors of included studies, they were excluded.

\section{Study selection and data extraction}

Two independent reviewers (VNL and BABR) applied the inclusion criteria and screened all titles and abstracts. Full texts were evaluated for potential inclusion and disagreements were resolved by consensus. If consensus was not reached, a third reviewer (RZP) was consulted.

Two independent reviewers (VNL and IRL) performed the data extraction of included studies using a standardised data extraction form. In case of disagreement, a third reviewer (RZP) arbitrated the decision. We extracted the following information from each eligible study: country, participants' characteristics (ie, age, sex and skill level), sample size (total and per group), characteristics of the intervention (focused or general exercises), number of non-contact injuries and exposure hours for each group, and study length. Interventions were categorised as general when the exercises targeted many body segments and joints, with no priority to train or protect a specific muscle group or joint. Focused interventions were defined as a set of exercises chosen to train and protect a specific muscle or joint. When exposure information was reported as 'athletic exposure' (ie, one athlete participating in one training or game), we converted the data using the assumption that one athletic exposure was equivalent to 2 hours of exposure. ${ }^{28}$

\section{Quality assessment}

The PEDro scale was used to assess the risk of bias of the included clinical trials. ${ }^{34}{ }^{35}$ All studies included in this review were listed in the PEDro database ${ }^{36}$; therefore, these assessments were adopted. ${ }^{35}$ Given the nature of the intervention assessed in this review, we adapted the scale and did not consider the items participant and therapist blinding, as it is not possible to blind participant and therapists in trials testing efficacy of exercise prevention programmes. Risk of bias of trials were confirmed by a reviewer (RZP) with 5 years of experience in rating trials using the PEDro scale.

The Grading of Recommendations Assessment, Development, and Evaluation (GRADE) approach was used to assess the overall quality of the evidence. ${ }^{3738}$ The GRADE tool is a systematic and explicit approach that allows judgements to be made about strength of evidence resulting from systematic reviews. Briefly, the GRADE classification was initially regarded as 'high' but downgraded by one level for each of the following domains we considered: (1) risk of bias (downgraded by one level when more than $25 \%$ of participants included in the meta-analysis were from studies with 'high risk of bias' (ie, when the study did not meet one or more of the following items: random allocation, allocation concealment, assessor blinding, complete outcome follow-up data and intention-to-treat analysis)); (2) inconsistency (downgraded by one level considering: the proportion of the observed variance may be substantial $\left(\mathrm{I}^{2}>50 \%\right)$, visual inspection for minimal or no overlap of CIs, and $\chi^{2}$ test ( $\mathrm{p}$ value $<0.05$ ); (3) indirectness (downgraded by one level if metaanalysis included participants with heterogeneous characteristics with regard to sex, age and level of sport (eg, men, women, youth, adults, amateur, professionals)); (4) imprecision (downgraded by one level when the clinical course of action differed considering the upper and lower $\mathrm{CI}$ as the true estimate, or the difference between upper and lower CI around the pooled 
estimate of the injury risk ratio (IRR) was $>0.5)^{28}$; and (5) publication bias (assessed funnel plot asymmetry by visual inspection and quantified using the Egger test ( $p$ value $<0.1$ ), if there were at least 10 studies in the meta-analysis).

The following categories were used to define the quality of evidence: high quality (ie, further research is unlikely to change our confidence in the estimate); moderate quality (ie, further research is likely to have an important impact on our confidence in the estimate and might change the estimate); low quality (ie, further research is likely to have an important impact on our confidence in the estimate and is likely to change the estimate); and very low quality (ie, we are uncertain about the estimate). ${ }^{3738}$

\section{Statistical analysis}

Number of non-contact injuries and exposure hours were used to calculate the injury incidence rate per 1000 hours and the IRR. The inverse variance random-effect model was used to compute the pooled IRR and 95\% CIs. As previously planned in our protocol, the available evidence allowed us to perform a subgroup analysis stratifying by intervention specificity (general vs focused exercises). Given that focused interventions targeted the hamstring muscles, subgroup analysis was restricted to noncontact hamstring injury. Heterogeneity between studies (ie, how much the effect size varies across studies) was estimated based on the proportion of the variation in point estimates due to between-study differences $\left(\mathrm{I}^{2}\right)$. Number needed to treat (NNT) analysis was performed by a mathematical formula. ${ }^{39}$ Meta-analyses were calculated using RevMan software, V.5.3.

\section{Deviation from protocol}

Post hoc sensitivity analyses were performed to investigate the effect of exercise-based programmes in the prevention of noncontact musculoskeletal injuries when (1) including only male or female participants, and (2) including only youth or adult participants. In addition, we decided to replace the terms unimodal and multimodal exercise programmes described in the registered protocol with the terms focused and general exercise programmes. Although the most appropriate terms to refer to these types of exercises may be open to question, the terms focused and general exercise programmes were considered more suitable for this review.

\section{RESULTS}

\section{Included studies}

The search strategy identified 7512 studies. After removal of duplicates, 4366 studies remained. Title and abstract screening identified 53 potentially eligible studies, and 10 original randomised controlled trials met the criteria to be included in this review (figure 1). In this review, a total of three studies were excluded due to lack of clear information.

The included studies were conducted in the USA, 3340 Norway, ${ }^{234}$ the Netherlands, ${ }^{24} 42$ Germany, ${ }^{43}$ Japan, ${ }^{44}$ Nigeria $^{45}$ and Sweden. ${ }^{46}$ Six studies included only male football players $^{24} 4042-45$ and four included only female football players, ${ }^{23} 334146$ and the total sample sizes for intervention and control groups were 6900 and 6455, respectively. One study

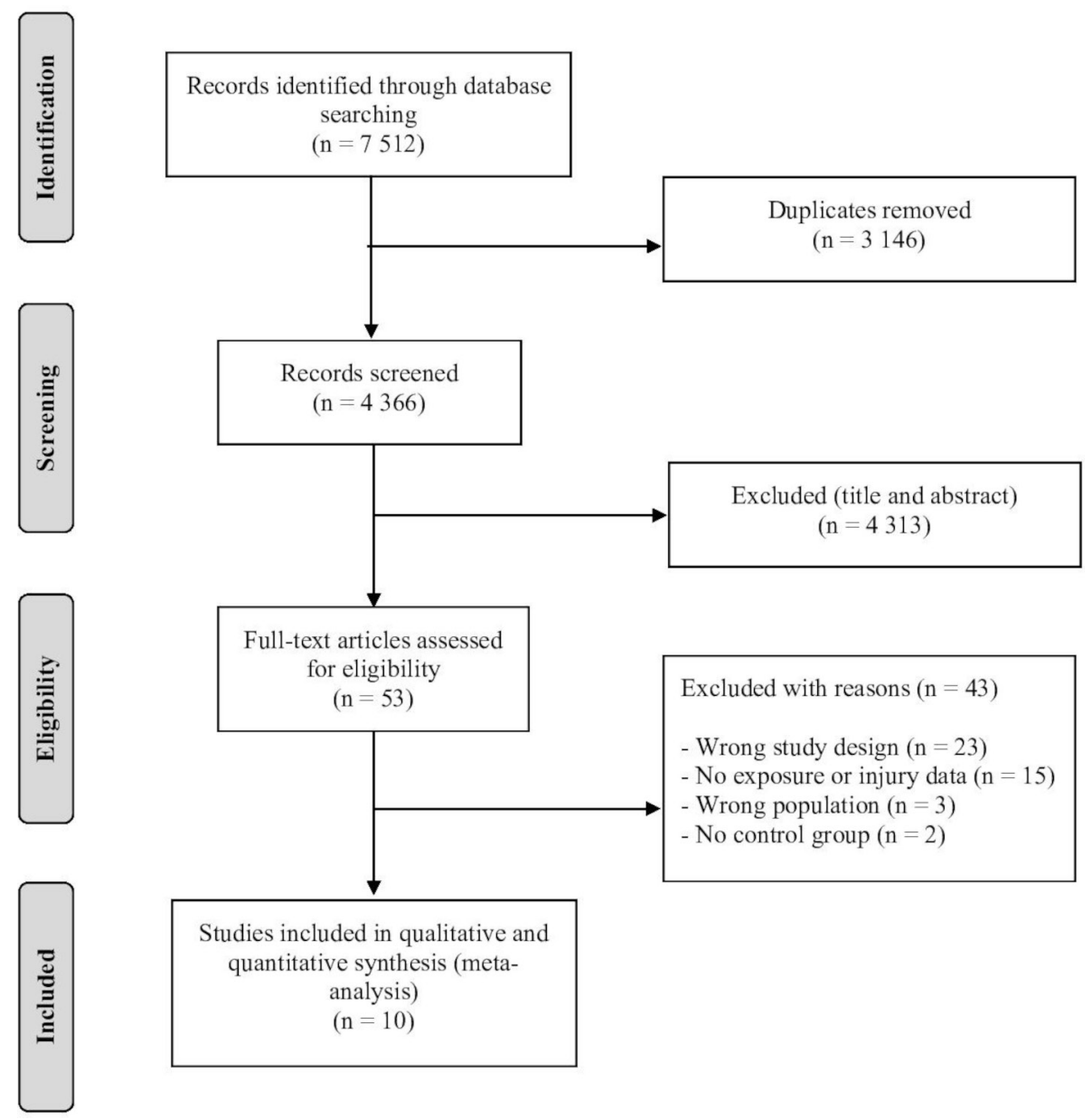

Figure 1 Flow chart of the included studies. 
Review

Table 1 Characteristics of the included studies

\begin{tabular}{|c|c|c|c|c|c|c|}
\hline Study, year & Country & $\begin{array}{l}\text { Participants } \\
\text { (all football players) }\end{array}$ & Sample size & Intervention & Study length & Outcome \\
\hline Gilchrist, $2008^{33}$ & USA & $\begin{array}{l}\text { Female collegiate } \\
\text { Age } \\
\text { IG: } 19.9 \\
\text { CG: } 19.9\end{array}$ & $\begin{array}{l}\text { IG: } 583 \\
\text { CG: } 852\end{array}$ & $\begin{array}{l}\text { General } \\
\text { Prevent Injury and } \\
\text { Enhance Performance } \\
\text { (PEP) Programme } \\
3 \text { times/week }\end{array}$ & 12 weeks & $\begin{array}{l}\text { Non-contact } \mathrm{ACL} \\
\text { injuries }\end{array}$ \\
\hline Hammes et al, $2015^{43}$ & Germany & $\begin{array}{l}\text { Male veteran }(\geq 32 \\
\text { years) } \\
\text { Age } \\
\text { IG: } 45.2 \pm 7.7 \\
\text { CG: } 43.1 \pm 6.5\end{array}$ & $\begin{array}{l}\text { IG: } 146 \\
\text { CG: } 119\end{array}$ & $\begin{array}{l}\text { General } \\
\text { FIFA } 11+ \\
\text { Every training session }\end{array}$ & 9 months & Overall injuries \\
\hline Hasebe et al, $2020^{44}$ & Japan & $\begin{array}{l}\text { Male high school } \\
\text { Age } \\
\text { IG: } 16.7 \pm 0.5 \\
\text { CG: } 16.3 \pm 0.6\end{array}$ & $\begin{array}{l}\text { IG: } 156 \\
\text { CG: } 103\end{array}$ & $\begin{array}{l}\text { Focused } \\
\text { Nordic Hamstring } \\
\text { Exercise } \\
\text { After training session } \\
2 \text { times/week }\end{array}$ & 27 weeks & $\begin{array}{l}\text { Overall hamstring } \\
\text { injuries }\end{array}$ \\
\hline Owoeye et al, $2014^{45}$ & Nigeria & $\begin{array}{l}\text { Male youth } \\
\text { Age } \\
\text { IG: } 17.8 \pm 0.9 \\
\text { CG: } 17.5 \pm 1.1\end{array}$ & $\begin{array}{l}\text { IG: } 212 \\
\text { CG: } 204\end{array}$ & $\begin{array}{l}\text { General } \\
\text { FIFA 11+ } \\
2 \text { times/week }\end{array}$ & 6 months & Overall injuries \\
\hline $\begin{array}{l}\text { Silvers-Granelli et al, } \\
2017^{40}\end{array}$ & USA & $\begin{array}{l}\text { Male collegiate } \\
\text { Age } \\
\text { IG: } 20.0 \pm 2.0 \\
\text { CG: } 21.0 \pm 1.0\end{array}$ & $\begin{array}{l}\text { IG: } 675 \\
\text { CG: } 850\end{array}$ & $\begin{array}{l}\text { General } \\
\text { FIFA 11+ } \\
\text { 2-3 times/week }\end{array}$ & 5 months & Overall $\mathrm{ACL}$ injuries \\
\hline Soligard et al, $2008^{23}$ & Norway & $\begin{array}{l}\text { Female youth } \\
\text { Age } \\
\text { IG: } 15.4 \pm 0.7 \\
\text { CG: } 15.4 \pm 0.7\end{array}$ & $\begin{array}{l}\text { IG: } 1055 \\
\text { CG: } 837\end{array}$ & $\begin{array}{l}\text { General } \\
\text { FIFA 11+ } \\
2 \text { times/week }\end{array}$ & 8 months & $\begin{array}{l}\text { Overall lower limb } \\
\text { injuries }\end{array}$ \\
\hline Steffen et al, $2008^{41}$ & Norway & $\begin{array}{l}\text { Female youth } \\
\text { Age } \\
\text { IG: } 15.4 \pm 0.8 \\
\text { CG: } 15.4 \pm 0.8\end{array}$ & $\begin{array}{l}\text { IG: } 1073 \\
\text { CG: } 947\end{array}$ & $\begin{array}{l}\text { General } \\
\text { FIFA } 11 \\
\text { Every training session for } \\
15 \text { consecutive sessions, } \\
\text { then } 1 \text { time/week for the } \\
\text { rest of the season }\end{array}$ & $\begin{array}{l}8 \text { months (including pre-season } \\
\text { and summer break) }\end{array}$ & Overall injuries \\
\hline van de Hoef et al, $2018^{42}$ & The Netherlands & $\begin{array}{l}\text { Male amateur } \\
\text { Age } \\
\text { IG: } 23.8 \pm 6.4 \\
\text { CG: } 22.2 \pm 3.1\end{array}$ & $\begin{array}{l}\text { IG: } 229 \\
\text { CG: } 171\end{array}$ & $\begin{array}{l}\text { Focused } \\
\text { Bounding Exercise } \\
\text { Programme (BEP) } \\
\text { Every training session }\end{array}$ & 39 weeks & $\begin{array}{l}\text { Overall hamstring } \\
\text { injuries }\end{array}$ \\
\hline $\begin{array}{l}\text { van der Horst et al, } \\
2015^{60}\end{array}$ & The Netherlands & $\begin{array}{l}\text { Male amateur } \\
\text { Age } \\
\text { IG: } 24.5 \pm 3.6 \\
\text { CG: } 24.6 \pm 4.1\end{array}$ & $\begin{array}{l}\text { IG: } 292 \\
\text { CG: } 287\end{array}$ & $\begin{array}{l}\text { Focused } \\
\text { Nordic Hamstring } \\
\text { Exercise } \\
\text { After training session } \\
2 \text { times/week }\end{array}$ & 13 weeks & $\begin{array}{l}\text { Overall hamstring } \\
\text { injuries }\end{array}$ \\
\hline Waldén et al, $2012^{46}$ & Sweden & $\begin{array}{l}\text { Female adolescents } \\
\text { Age } \\
\text { IG: } 14.0 \pm 1.2 \\
\text { CG: } 14.1 \pm 1.2\end{array}$ & $\begin{array}{l}\text { IG: } 2479 \\
\text { CG: } 2085\end{array}$ & $\begin{array}{l}\text { General } \\
\text { Neuromuscular training } \\
\text { (Knäkontroll) } \\
2 \text { times/week }\end{array}$ & 7 months & Overall knee injuries \\
\hline
\end{tabular}

CG, control group; IG, intervention group.

used veteran players, ${ }^{43}$ two used adult players ${ }^{24} 42$ and seven used youth players (eg, high school or collegiate). $.^{23} 33404144-46$ All studies included amateur players. Three studies used a focused exercise programme, ${ }^{24} 4244$ while seven used a general intervention. $^{23} 334041434546$ The intervention period ranged from 12 weeks to 9 months (table 1 ).

Three ongoing trials were identified in clinical registries: one from Sweden and two from Saudi Arabia. The status for all registered trials is 'Not yet recruiting' (online supplemental table 2).

\section{Study characteristics}

Four studies used the FIFA $11+$ warmup and strengthening programme, 23404345 two studies used the Nordic Hamstring Exercise, ${ }^{24}$ one study used the FIFA 11 programme, ${ }^{41}$ one study used the Prevention Injury and Enhance Performance programme, ${ }^{33}$ one study used the Bounding Exercise
Programme ${ }^{42}$ and one study used a neuromuscular training programme (Knäkontroll). ${ }^{46}$ Focused prevention programmes consisted of exercises for the quadriceps or hamstring muscles, while general programmes involved agility, balance, mobility, plyometrics, running and strength exercises for the lower limb. All interventions were applied at least twice a week to every training session. A total of 545 non-contact injuries and 1062711 hours of exposure were computed.

Outcomes of the included studies were overall injuries, ${ }^{41} 4345$ overall lower limb injuries, ${ }^{23}$ overall hamstring injuries, ${ }^{24} 4244$ overall knee injuries, ${ }^{46}$ overall ACL injuries ${ }^{40}$ and non-contact ACL injuries. ${ }^{33}$ Regarding comparators, control groups were instructed to perform their usual warm-up exercises 23341 and/or training routines. ${ }^{24} 42434546$ Two studies did not provide information on control groups. ${ }^{40} 44$ 


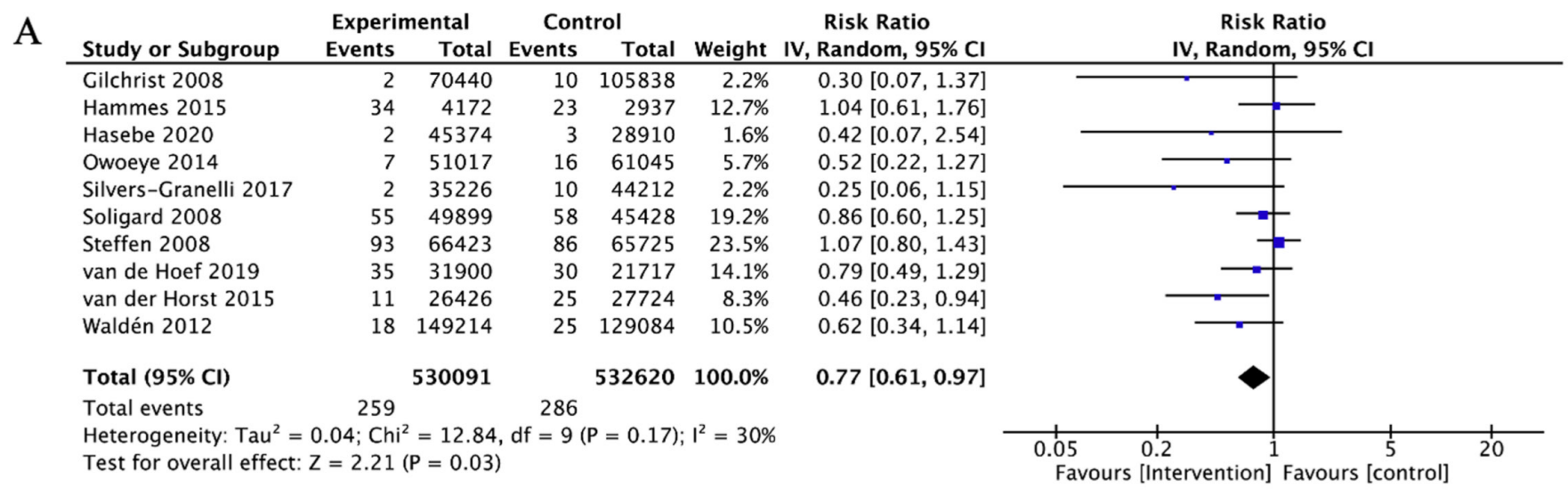

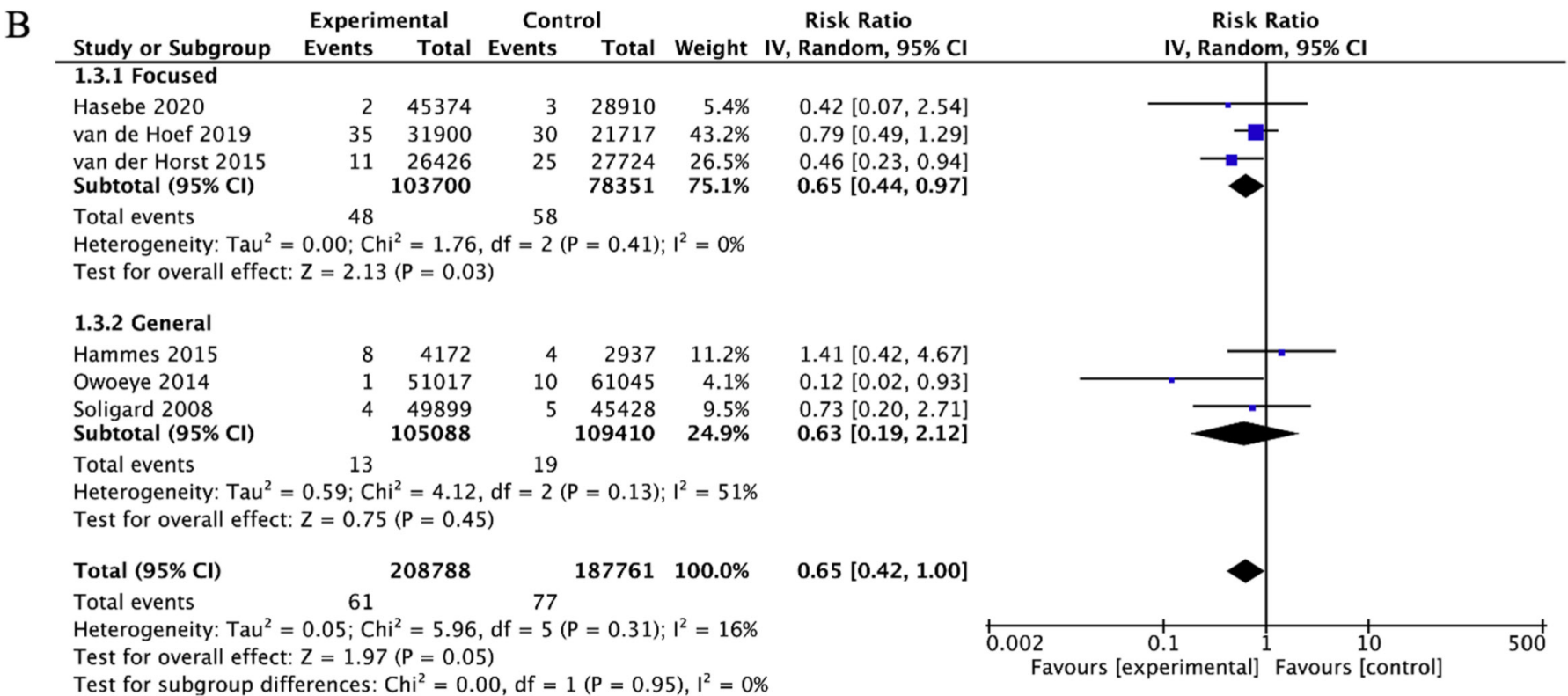

Figure 2 Meta-analysis investigating the effect of exercise-based prevention programmes compared with a control group in reducing (A) overall non-contact injuries and (B) non-contact hamstring injuries in football players. The size of the blue boxes is proportional to the weight of each study in the analysis.

\section{Quality assessment}

Overall risk of bias of individual included studies is shown in online supplemental table 3 . All studies had random allocation, $30 \%$ had concealed allocation, $40 \%$ blinded the assessors, $50 \%$ had complete outcome follow-up data and $70 \%$ had intentionto-treat analysis. Due to the nature of the interventions, none of the included studies were blinded for participants and therapists.

\section{Effect of exercise-based prevention programmes on non-} contact musculoskeletal injuries

The results of meta-analysis pooling data from 10 trials showed very low-quality evidence (ie, downgraded one level due to risk of bias, one level due to indirectness and one level due to publication bias (online supplemental figure 1) that exercise-based prevention programmes reduce, on average, the risk of noncontact musculoskeletal injuries by $23 \%$ (IRR $0.77 ; 95 \%$ CI 0.61 to $0.97 ; n=13355 ; I^{2}=30 \%$ ) compared with the control group (figure 2A).

There is low-quality evidence (ie, downgraded one level due to risk of bias and one level due to imprecision) that focused programmes reduce the risk of non-contact hamstring injuries by $35 \%$ (IRR $0.65 ; 95 \%$ CI 0.44 to $0.97 ; n=1238 ; I^{2}=0 \%$ ) compared with the control group. There is very low-quality evidence (ie, downgraded one level due risk of bias, one level due to inconsistency, one level due to indirectness and one level due to imprecision) that general programmes were not more effective than control group (IRR $0.63 ; 95 \%$ CI 0.19 to 2.12 ; $\left.\mathrm{n}=2573 ; \mathrm{I}^{2}=51 \%\right)$. Focused programmes were not different from general interventions for the prevention of non-contact hamstring injuries ( $\mathrm{p}$ value $=0.95$ ) (figure $2 \mathrm{~B}$ ). Detailed information regarding the quality of evidence (GRADE) is shown in table 2. The NNT value was 148 for overall intervention programmes and 31 for focused programmes. The NNT values for men and women were 118 and 181, respectively, for overall intervention programmes.

\section{Sensitivity analysis}

The pooled effect restricted to studies with male athletes showed an IRR of 0.68 ((95\% CI 0.48 to 0.96$\left.) ; n=3444 ; I^{2}=20 \%\right)$ favouring exercise-based prevention programmes over control, while for studies with female athletes the IRR was $0.85((95 \%$ CI 0.63 to 1.16 ); $n=9911 ; I^{2}=38 \%$ ) (online supplemental figure 
Table 2 Summary of findings and quality of evidence (GRADE)

\begin{tabular}{|c|c|c|c|c|c|c|c|c|c|}
\hline \multirow[b]{2}{*}{ Meta-analysis } & \multicolumn{5}{|c|}{ Quality assessment } & \multicolumn{2}{|c|}{ Participants, n } & \multirow{2}{*}{$\begin{array}{l}\text { Effect } \\
\text { IRR }(95 \% \mathrm{Cl})\end{array}$} & \multirow[b]{2}{*}{$\begin{array}{l}\text { GRADE } \\
\text { Quality }\end{array}$} \\
\hline & $\begin{array}{l}\text { Risk of } \\
\text { bias* }\end{array}$ & Inconsistency† & Indirectnessł & Imprecision§ & $\begin{array}{l}\text { Publication } \\
\text { biasfl }\end{array}$ & IG & CG & & \\
\hline $\begin{array}{l}\text { Exercise-based prevention } \\
\text { programmes } 10 \text { studies }\end{array}$ & O & $\oplus$ & $\bigcirc$ & $\oplus$ & $\bigcirc$ & 6900 & 6455 & 0.77 (0.61 to 0.97$)$ & $\begin{array}{l}\text { Very low } \\
\oplus \oplus \bigcirc \bigcirc \bigcirc\end{array}$ \\
\hline $\begin{array}{l}\text { Focused programmes for non- } \\
\text { contact hamstring injuries } \\
\text { three studies }\end{array}$ & $\bigcirc$ & $\oplus$ & $\oplus$ & $\bigcirc$ & - & 677 & 561 & $0.65(0.44$ to 0.97$)$ & $\begin{array}{l}\text { Low } \\
\oplus \oplus \bigcirc \bigcirc\end{array}$ \\
\hline $\begin{array}{l}\text { General programmes for non- } \\
\text { contact hamstring injuries } \\
\text { three studies }\end{array}$ & ○ & 0 & $\bigcirc$ & O & - & 1413 & 1160 & 0.63 (0.19 to 2.12$)$ & $\begin{array}{l}\text { Very low } \\
\bigcirc 00 \bigcirc\end{array}$ \\
\hline \multicolumn{10}{|c|}{$\begin{array}{l}\text { *More than } 25 \% \text { of participants from studies with 'high risk of bias'. } \\
\text { †Downgraded by one level considering: the proportion of the observed variance may be substantial }\left(I^{2}>50 \%\right) \text {, visual inspection for minimal or no overlap of Cls, } \\
\text { ¥Based on the characteristics of participants included in the meta-analysis. } \\
\text { §Downgraded if the upper and lower Cls had }>0.5 \text { difference; or if the clinical course of action differed considering the upper and lower } \mathrm{Cl} \text { as the true estimate. } \\
\text { IAssessed with visual inspection of the funnel plot and two-tailed Egger test (if }>10 \text { studies were included in the meta-analysis). } \\
\text { CG, control group; IG, intervention group; IRR, injury risk ratio. }\end{array}$} \\
\hline
\end{tabular}

2). The IRR for studies with youth and adult participants were 0.75 ((95\% CI 0.54 to 1.02$\left.) ; n=12111 ; \mathrm{I}^{2}=36 \%\right)$ and 0.77 ((95\% CI 0.51 to 1.16$\left.) ; \mathrm{n}=1244 ; \mathrm{I}^{2}=39 \%\right)$, respectively (online supplemental figure 3$)$.

\section{Incidence of non-contact injuries}

The incidence rate of non-contact injuries in this review (for control groups only) was 0.54 (95\% CI 0.47 to 0.60$)$ per 1000 hours of exposure (table 3 ). When considering studies with overall non-contact injuries as outcome, ${ }^{4143} 45$ the injury incidence rate was 0.96 (95\% CI 0.79 to 1.13 ) per 1000 hours of exposure. The average incidence rate of non-contact injuries for male (age range 16.3-43.1 years) ${ }^{24} 4042-45$ and female (age range 14.1-19.9) 23334146 participants were 0.57 (95\% CI 0.46 to 0.68 ) and 0.52 (95\% CI 0.44 to 0.59 ) per 1000 hours of exposure, respectively. Among youth and adult participants, the incidence rates were 0.43 (95\% CI 0.37 to 0.49 ) and 1.49 (95\% CI 1.16 to 1.82 ) per 1000 hours of exposure, respectively. The average incidence rates of non-contact injuries to the hamstring $232442-45$ and $\mathrm{ACL}^{4041}$ were 0.41 (95\% CI 0.32 to 0.50$)$ and 0.87 (95\% CI 0.70 to 1.05$)$ per 1000 hours of exposure, respectively. Detailed information is shown in table 3.

\section{DISCUSSION}

\section{Statement of principal findings}

This systematic review shows that exercise-based prevention programmes may be effective in reducing the risk of noncontact musculoskeletal injuries by $23 \%$ (95\% CI 3\% to 39\%) among football players when compared with a control group. This result is based on very low-quality evidence and more high-quality studies in this area are needed to clarify the role of exercise-based programmes in preventing non-contact musculoskeletal injuries. Hamstring-focused programmes did not reduce hamstring injury any more than general programmes. The incidence rate of overall non-contact injuries, for control groups only, was 0.96 per 1000 hours of exposure.

\section{Strengths and limitations of the review and the available evidence}

The strengths of this systematic review include the use of a prespecified protocol with no language and date restriction criteria, the inclusion of only randomised controlled trials, the assessment of risk of bias and overall quality of the evidence. On the other hand, this review has limitations that should be considered. Although most of the included studies $(80 \%, \mathrm{n}=8)$ used the consensus statement proposed by Fuller et $a l^{47}$ to define injuries, $60 \%(n=6)$ focused on specific type of injuries (hamstring, knee or ACL) and did not report other non-contact injuries. This may have influenced the pooled estimated found in this review. Future studies should investigate and report data for all non-contact injuries to allow estimates to be calculated for overall and specific types of non-contact injuries. We only included lower limb non-contact injuries, and most of participants were women and young amateur athletes, which limits the generalisability of our findings. Nevertheless, the majority of injuries in football affect the lower extremities, and there are more amateur than professional players worldwide (265 million vs 200000$).{ }^{48}$ Finally, we used visual inspection and statistical test for asymmetry of funnel plots to assess publication bias. These approaches are prone to error and their results should be interpreted with caution.

A limitation of the available evidence is the high risk of bias (4 of the 10 studies) and small number of studies included in the meta-analysis. Despite the advance in football prevention strategies, there is still a lack of randomised trials investigating non-contact musculoskeletal injuries, especially among high-risk populations (eg, elite youth female players). ${ }^{49}$ Ninety per cent $(n=9)$ of the included studies did not report non-contact injuries in training and matches separately; therefore, we were not able to report injury incidence separately for training and matches. Finally, our search strategy identified three ongoing trials that might change our current estimates and should be considered for future reviews.

\section{Comparison with previous reviews on injury risk reduction}

Our results showed an estimated risk reduction of $23 \%$ in the prevention of non-contact musculoskeletal injuries favouring exercise-based programmes over control, but the true effect could vary largely from $3 \%$ to $39 \%$. This estimate is lower than a previous systematic review showing a $37 \%$ risk reduction for exercise-based programmes on prevention of sport injuries. ${ }^{50}$ The diversity of interventions, sports and participation level may help to explain the higher heterogeneity $\left(\mathrm{I}^{2}=70 \% ; \mathrm{p}<0.001\right)$ of this previous review in comparison to our results. In football, specifically, there is evidence that exercise-based prevention programmes reduced overall injuries by $22 \%$ and $25 \%$ among women and recreational/subelite athletes, respectively. ${ }^{22} 28$ These results combined evidence from overall injuries and different 


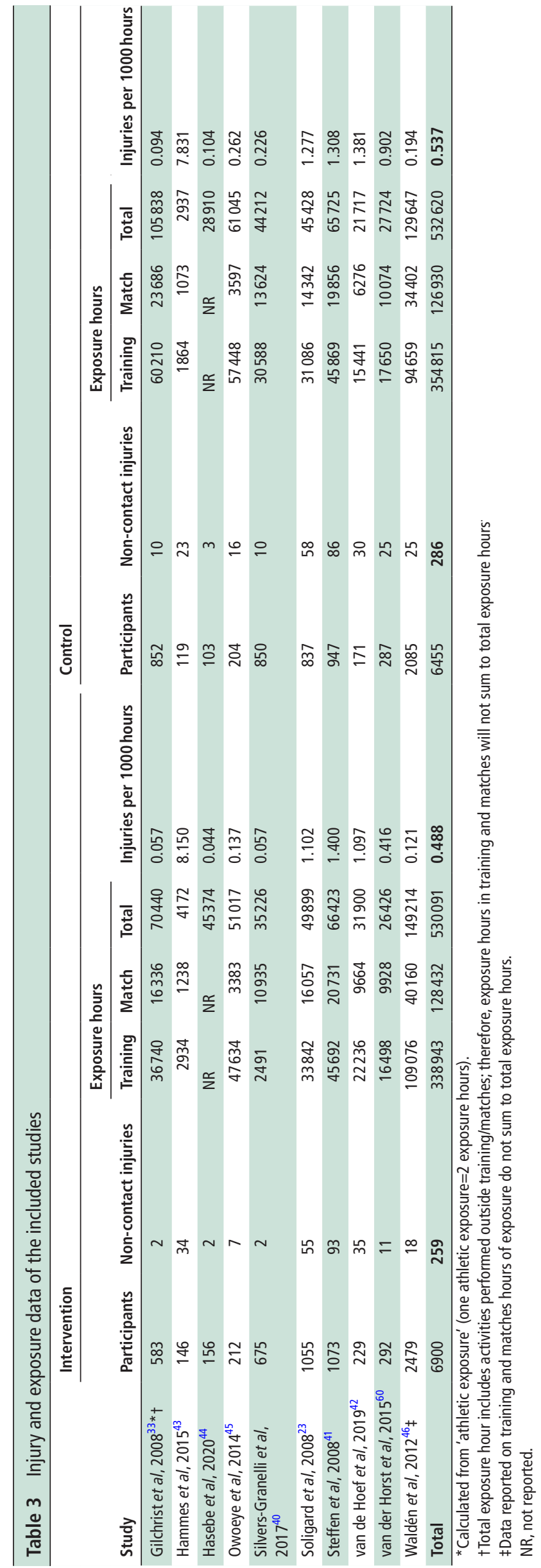

interventions, which might be related to the significant heterogeneity $\left(\mathrm{I}^{2}=60.3 \%\right.$ and $\left.68.9 \%\right){ }^{22}{ }^{28}$ Our review presents low heterogeneity probably due to inclusion of specific football injuries (ie, non-contact). Our results could be interpreted as promising, but future high-quality studies are needed to determine whether the results are clinically relevant to be applied in the sport settings. For instance, the NNT analysis indicated that at least 148 football athletes are needed to be exposed to intervention to prevent one non-contact musculoskeletal injury, which is considerably higher than previously pooled NNT estimates on non-contact injury $(\mathrm{NNT}=89) .{ }^{51}$

Interestingly, our sensitivity results for gender showed that exercise-based prevention programmes were not more effective to prevent non-contact injuries compared with control in female athletes. The four trials included in the sensitivity analysis were conducted with female amateur athletes and three of these trials were considered to be of high risk of bias (ie, no concealed allocation, no assessor blinding, no adequate follow-up, or no intention-to-treat analysis). Our results contrast with a previous review showing that exercise-based prevention programmes reduce overall injuries by $22 \%$ in female football players. ${ }^{28}$ In addition, there is evidence that a subgroup of female athletes, that is, elite youth female athletes, are at a higher risk of injury. ${ }^{49}$ More high-quality studies are needed, especially with high-risk subgroups (eg, youth elite female athletes), to strengthen our findings and to provide information on how health and football policy makers can adopt and optimise exercise-based prevention programmes across all ages and skill levels (ie, amateurs vs professionals and youth vs adult players).

The pooled effect calculated in the sensitivity analyses showed considerable overlap of $95 \% \mathrm{CI}$, which means that the available studies do not clearly show differences according to sex and age.

\section{General versus focused exercise programmes}

Our subgroup analysis did not reveal significant difference between focused and general interventions (substantial overlap between both estimates). Our analysis for the subgroup of focused intervention included three studies focusing on hamstring exercises (ie, Nordic Hamstring Exercise and Bounding Exercise Programme $)^{24} 4244$ and showed low-quality evidence that the focused interventions may reduce the risk of non-contact injuries, in this case hamstring injuries, by 35\% (95\% CI 3\% to 56\%) when compared with the control group. A previous systematic review has shown that injury prevention programmes that include Nordic Hamstring Exercise decreased the risk of hamstring injuries by $51 \%$ when compared with the control group. ${ }^{21}$ This estimate is higher than the estimate found in our review and might be due to differences in study designs, mechanism of injury and participants. We included only randomised controlled trials, noncontact injuries and both sexes, while previous reviews included both randomised and prospective cohort studies, ${ }^{21}$ overall injuries (ie, contact and non-contact) ${ }^{21} 28$ and only women. ${ }^{28}$ The pooled NNT estimates for focused programmes showed that 31 athletes would need to participate in the intervention to prevent one non-contact hamstring injury, which is slightly higher than previous individual evidence of specific exercise (ie, eccentric training) on hamstring injuries (NNT $=13) .^{52}$

Given that NNT is highly dependent on the incidence of an outcome, and not only on the efficacy of an intervention, the NNT values in this review should be interpreted with caution. Considering that incidence may vary according to type of injury, characteristics of participants and sport, comparisons of NNT should be done between similar outcomes, participants and sports. 


\section{Incidence of non-contact injuries in football}

The incidence of non-contact injuries in this review (0.54 per 1000 hours) is higher than those observed for overall injuries in amateur players ( 0.49 per 1000 hours) ${ }^{53}$ and lower than observed for non-contact (7.4 per 1000 hours) ${ }^{54}$ and overall ( 8.1 per 1000 hours $^{7}$ injuries in professional football players. None of the studies in this review included professional players, which may explain these differences. We would argue that professionals play at the highest level and, therefore, are more susceptible to injuries than amateur players. The highest incidence in our study was for non-contact ACL injuries (0.87 per 1000 hours), which is lower than previous findings showing an incidence rate of $\sim 1.5$ per 1000 hours across a seven-season study with professional players. ${ }^{9}$ Among a total of 4483 injuries observed, 18\% $(n=828)$ were ligament-related injuries (eg, sprain/ligament injury). ${ }^{9}$ Since the majority of ligament injuries (ie, 64\%) occurs in non-contact situations, ${ }^{11}$ more high-quality randomised trials should be conducted to investigate the efficacy of exercise-based programmes in preventing non-contact ACL injuries among amateur and professional football players. It is important to mention that only $55 \%$ of athletes who undergo ACL reconstruction return to competitive pre-injury level, ${ }^{55}$ which may cause some athletes to not progress on to professional level when suffering an ACL injury at lower levels of competition.

Although this review reported injury incidence for overall noncontact injuries from control group data, many of the included trials reported only a subset of non-contact injuries (eg, hamstring or $\mathrm{ACL}$ ); thus, the injury incidence rates do not reflect the true rate of overall non-contact injuries. It is possible that non-contact injuries which were actually sustained during the exposure time included in this review were not recorded. Even for overall non-contact injuries, there is an inherent limitation of incidence rates due to differences in reporting systems, injury definition and athletes' perception.

\section{Implications for clinicians}

Given that football is the most popular recreational and amateur sport worldwide and provides important health benefits, ${ }^{5657}$ welldocumented strategies to reduce injuries among football players, especially amateurs, is of utmost importance to sports and public health. Based on the findings of our review and the available evidence, ${ }^{132154}$ we recommend that exercise-based programmes should be implemented in amateur football to reduce non-contact musculoskeletal injuries. Although this recommendation is based on very low-quality evidence, we should not diminish the merits of exercise-based programmes in preventing sports injuries. The very low-quality evidence strengthens the need for more high-quality research on this topic. Regarding specificity of exercise-based programmes (ie, general or focused), our findings suggest that there might be a role for focused interventions, such as hamstring-specific exercises (ie, eccentric), when the aim is to prevent non-contact hamstring injuries, which is the most prevalent non-contact injury in football. ${ }^{10} 11$ Since athletes with history of hamstring injury are 2.7 times more likely to re-injury, ${ }^{58}$ we would argue that it might be feasible to incorporate hamstring-focused exercises to exercise-based prevention programmes for preventing occurrence and recurrence of this type of injury. Based on the available evidence on the efficacy of general exercises for reducing the risk of overall non-contact musculoskeletal injuries, ${ }^{22} 28$ our view is that exercise-based prevention programmes with general exercises (eg, eccentric strengthening, plyometrics, running, agility and neuromuscular training) would be more feasible to implement for amateur football players because exercises are often easy to perform and may require less supervision. Interestingly, adherence to general and focused exercises may vary. Previous research has shown that adherence to general exercises is up
What is already known?

- More than $90 \%$ of all muscle injuries and $51 \%-64 \%$ of joint/ ligament injuries (ie, ACL) in football (soccer) occur in noncontact situations.

- Exercise-based prevention programmes reduce the overall injury rate.

- There is no systematic review assessing the efficacy of exercise-based programmes in the prevention of non-contact musculoskeletal injuries among football players.

\section{What are the new findings?}

Exercise-based prevention programmes reduce, on average, the risk of non-contact musculoskeletal injuries by $23 \%$.

- Focused exercise-programmes reduce the risk of non-contact hamstring injuries by $35 \%$.

- The injury incidence rate of overall non-contact injuries (for control group only) was 0.96 per 1000 hours of exposure.

to $85 \%,{ }^{59}$ while adherence to focused exercise (ie, Nordic Hamstring Exercise) is $69 \%$ among amateur football players. ${ }^{60}$ Clinicians should consider using, in addition to athletes' preferences for exercises, the top strategies to maximise player adherence to injury prevention programmes: education, trust and communication, and coach attendance at sessions. ${ }^{61}$

\section{CONCLUSION}

Exercise-based prevention programmes reduce non-contact musculoskeletal injuries by $23 \%$ (95\% CI $3 \%$ to $39 \%$ ) in amateur football players. Despite this evidence being rated as very low quality and considering the burden that an injury may have on athletes' health, exercise-based prevention programmes should be implemented in football settings. Given the number of ongoing trials, the estimate of effect found in this review is likely to change once the results of these trials become available. At present, it is still unclear whether focused or general programmes provide greater reduction in overall non-contact musculoskeletal injuries. Further research investigating the efficacy of these programmes in amateur and professional settings are warranted to provide a more directive clinical recommendation.

Twitter Italo Ribeiro Lemes @itolemes, Rafael Zambelli Pinto @Rafael_Z_Pinto, Evert Verhagen @Evertverhagen and Caroline Bolling @cs_bolling

Acknowledgements The authors acknowledge the Coordination for the Improvement of Higher Education Personnel (CAPES) - Finance code 001, and the corresponding authors of included studies for their help in data acquisition. STF and RZP are fellowship recipients from the National Council for Scientific and Technological Development (CNPq).

Contributors IRL, RZP, VNL, BABR and TRS conceived and designed the study. IRL and VNL conducted the search. IRL, VNL and BABR performed the screening, study selection and data extraction. IRL, RZP, STF and TRS analysed and interpreted the data. IRL, RZP and TRS drafted the manuscript with input from STF, EV, CB and CFA. All authors have read and approved the final version.

Funding The authors have not declared a specific grant for this research from any funding agency in the public, commercial or not-for-profit sectors.

Competing interests None declared.

Patient consent for publication Not required.

Provenance and peer review Not commissioned; externally peer reviewed. 
Supplemental material This content has been supplied by the author(s). It has not been vetted by BMJ Publishing Group Limited (BMJ) and may not have been peer-reviewed. Any opinions or recommendations discussed are solely those of the author(s) and are not endorsed by BMJ. BMJ disclaims all liability and responsibility arising from any reliance placed on the content. Where the content includes any translated material, BMJ does not warrant the accuracy and reliability of the translations (including but not limited to local regulations, clinical guidelines, terminology, drug names and drug dosages), and is not responsible for any error and/or omissions arising from translation and adaptation or otherwise.

\section{ORCID iDs}

Italo Ribeiro Lemes http://orcid.org/0000-0001-9245-287X

Rafael Zambelli Pinto http://orcid.org/0000-0002-2775-860X

Evert Verhagen http://orcid.org/0000-0001-9227-8234

Sérgio T Fonseca http://orcid.org/0000-0002-2979-8744

Thales R Souza http://orcid.org/0000-0001-8081-1687

\section{REFERENCES}

1 Stølen T, Chamari K, Castagna C. Physiology of soccer. Sports Medicine 2005;35:501-36.

2 Dvorak J, Junge A, Graf-Baumann T, et al. Editorial. Am I Sports Med 2004:32:3-4.

3 Oja P, Titze S, Kokko S, et al. Health benefits of different sport disciplines for adults: systematic review of observational and intervention studies with meta-analysis. $\mathrm{Br} J$ Sports Med 2015;49:434-40.

4 Pedersen MT, Vorup J, Nistrup A, et al. Effect of team sports and resistance training on physical function, quality of life, and motivation in older adults. Scand J Med Sci Sports 2017;27:852-64.

5 Eime RM, Young JA, Harvey JT, et al. A systematic review of the psychological and social benefits of participation in sport for children and adolescents: informing development of a conceptual model of health through sport. Int I Behav Nutr Phys Act 2013;10:98

6 Turi-Lynch BC, Monteiro HL, Fernandes RA, et al. Impact of sports participation on mortality rates among Brazilian adults. J Sports Sci 2019;37:1443-8.

7 López-Valenciano A, Ruiz-Pérez I, Garcia-Gómez A, et al. Epidemiology of injuries in professional football: a systematic review and meta-analysis. Br I Sports Med 2020:54:711-8.

8 van Beijsterveldt AMCA-M, Stubbe JH, Schmikli SL, et al. Differences in injury risk and characteristics between Dutch amateur and professional soccer players. I Sci Med Sport 2015;18:145-9.

9 Ekstrand J, Hägglund M, Waldén M. Injury incidence and injury patterns in professional football: the UEFA injury study. Br J Sports Med 2011;45:553-8.

10 Stubbe JH, van Beijsterveldt A-MMC, van der Knaap S, et al. Injuries in professional male soccer players in the Netherlands: a prospective cohort study. J Athl Train 2015;50:211-6

11 Ekstrand J, Hägglund M, Waldén M. Epidemiology of muscle injuries in professional football (soccer). Am J Sports Med 2011;39:1226-32.

12 Rekik RN, Tabben M, Eirale C, et al. ACL injury incidence, severity and patterns in professional male soccer players in a middle Eastern League. BMJ Open Sport Exerc Med 2018:4:e000461.

13 Waldén M, Krosshaug T, Bjørneboe J, et al. Three distinct mechanisms predominate in non-contact anterior cruciate ligament injuries in male professional football players: a systematic video analysis of 39 cases. Br I Sports Med 2015;49:1452-60

14 Jones S, Almousa S, Gibb A, et al. Injury incidence, prevalence and severity in highlevel male youth football: a systematic review. Sports Med 2019;49:1879-99.

15 Sherry MA, Johnston TS, Heiderscheit BC. Rehabilitation of acute hamstring strain injuries. Clin Sports Med 2015;34:263-84.

16 Psychological issues related to illness and injury in athletes and the team physician: a consensus Statement-2016 update. Med Sci Sport Exerc 2017;49:1043-54.

17 Hägglund $\mathrm{M}$, Waldén $\mathrm{M}$, Magnusson $\mathrm{H}$, et al. Injuries affect team performance negatively in professional football: an 11-year follow-up of the UEFA champions League injury study. Br J Sports Med 2013;47:738-42.

18 Sepúlveda F, Sánchez L, Amy E, et al. Anterior cruciate ligament injury: return to play, function and long-term considerations. Curr Sports Med Rep 2017;16:172-8.

19 Drawer S, Fuller CW. Propensity for osteoarthritis and lower limb joint pain in retired professional soccer players. Br J Sports Med 2001;35:402-8

20 Eliakim E, Morgulev E, Lidor R, et al. Estimation of injury costs: financial damage of English Premier League teams' underachievement due to injuries. BMJ Open Sport Exerc Med 2020;6:e000675.

21 Al Attar WSA, Soomro N, Sinclair PJ, et al. Effect of injury prevention programs that include the Nordic hamstring exercise on hamstring injury rates in soccer players: a systematic review and meta-analysis. Sports Med 2017;47:907-16.

22 Thorborg K, Krommes KK, Esteve E, et al. Effect of specific exercise-based football injury prevention programmes on the overall injury rate in football: a systematic review and metaanalysis of the FIFA 11 and 11+ programmes. Br J Sports Med 2017;51:562-71.
23 Soligard T, Myklebust G, Steffen K, et al. Comprehensive warm-up programme to prevent injuries in young female footballers: cluster randomised controlled trial. $B M J$ 2008;337:a2469.

24 van der Horst N, Smits D-W, Petersen J, et al. The preventive effect of the Nordic hamstring exercise on hamstring injuries in amateur soccer players: a randomized controlled trial. Am J Sports Med 2015;43:1316-23.

25 Al Attar WSA, Alshehri MA. A meta-analysis of meta-analyses of the effectiveness of FIFA injury prevention programs in soccer. Scand J Med Sci Sports 2019;29:1846-55.

26 van Beijsterveldt AMC, van der Horst N, van de Port IGL, et al. How effective are exercise-based injury prevention programmes for soccer players? : A systematic review. Sports Med 2013;43:257-65.

27 Gomes Neto M, Conceição CS, de Lima Brasileiro AJA, et al. Effects of the FIFA 11 training program on injury prevention and performance in football players: a systematic review and meta-analysis. Clin Rehabil 2017:31:651-9.

28 Crossley KM, Patterson BE, Culvenor AG, et al. Making football safer for women: a systematic review and meta-analysis of injury prevention programmes in 11773 female football (soccer) players. Br J Sports Med 2020;54:1089-98.

29 Eirale C, Gillogly S, Singh G, et al. Injury and illness epidemiology in soccer - effects of global geographical differences - a call for standardized and consistent research studies. Biol Sport 2017;34:249-54.

30 Reis GF, Santos TRT, Lasmar RCP, et al. Sports injuries profile of a first division Brazilian soccer team: a descriptive cohort study. Braz J Phys Ther 2015;19:390-7.

31 Moher D, Liberati A, Tetzlaff J, et al. Preferred reporting items for systematic reviews and meta-analyses: the PRISMA statement. Ann Intern Med 2009;151:264.

32 Oliveira CB, Elkins MR, Lemes Ítalo Ribeiro, et al. A low proportion of systematic reviews in physical therapy are registered: a survey of 150 published systematic reviews. Braz J Phys Ther 2018;22:177-83.

33 Gilchrist J, Mandelbaum BR, Melancon $\mathrm{H}$, et al. A randomized controlled trial to prevent noncontact anterior cruciate ligament injury in female collegiate soccer players. Am J Sports Med 2008;36:1476-83.

34 Macedo LG, Elkins MR, Maher CG, et al. There was evidence of convergent and construct validity of physiotherapy evidence database quality scale for physiotherapy trials. J Clin Epidemiol 2010;63:920-5.

35 Maher CG, Sherrington C, Herbert RD, et al. Reliability of the PEDro scale for rating quality of randomized controlled trials. Phys Ther 2003;83:713-21.

36 Moseley AM, Elkins MR, Van der Wees PJ. Using research to guide practice: the physiotherapy evidence database (PEDro). Brazilian J Phys Ther 2019.

37 Atkins $D$, Best D, Briss PA, et al. Grading quality of evidence and strength of recommendations. BMJ 2004:328:1490.

38 Guyatt $\mathrm{GH}, \mathrm{Oxman} A \mathrm{D}$, Kunz $\mathrm{R}$, et al. What is "quality of evidence" and why is it important to clinicians? BMJ 2008:336:995-8.

39 Chatellier G, Zapletal E, Lemaitre D, et al. The number needed to treat: a clinically useful nomogram in its proper context. BMJ 1996;312:426-9.

40 Silvers-Granelli HJ, Bizzini M, Arundale A, et al. Does the FIFA 11+ Injury Prevention Program Reduce the Incidence of ACL Injury in Male Soccer Players? Clin Orthop Relat Res 2017:475:2447-55

41 Steffen $\mathrm{K}$, Myklebust G, Olsen OE, et al. Preventing injuries in female youth football--a cluster-randomized controlled trial. Scand J Med Sci Sports 2008;18:605-14.

42 van de Hoef PA, Brink MS, Huisstede BMA, et al. Does a bounding exercise program prevent hamstring injuries in adult male soccer players? - A cluster-RCT. Scand J Med Sci Sports 2019:29:515-23.

43 Hammes D, Aus der Fünten K, Kaiser S, et al. Injury prevention in male veteran football players - a randomised controlled trial using "FIFA 11+". J Sports SCi 2015;33:873-81.

44 Hasebe $\mathrm{Y}$, Akasaka K, Otsudo T, et al. Effects of Nordic hamstring exercise on hamstring injuries in high school soccer players: a randomized controlled trial. Int J Sports Med 2020;41:154-60.

45 Owoeye OBA, Akinbo SRA, Tella BA, et al. Efficacy of the FIFA 11+ warm-up programme in male youth football: a cluster randomised controlled trial. I Sports SC Med 2014;13:321-8.

46 Waldén M, Atroshi I, Magnusson H, et al. Prevention of acute knee injuries in adolescent female football players: cluster randomised controlled trial. BMJ 2012;344:e3042.

47 Fuller CW, Ekstrand J, Junge A, et al. Consensus statement on injury definitions and data collection procedures in studies of football (soccer) injuries. Br J Sports Med 2006;40:193-201

48 Fédération Internationale de Football Association (FIFA). FIFA big count 2006: 270 million people active in football. FIFA Commun Div Inf Serv 2007.

49 Bricca $A$, Juhl CB, Bizzini $M$, et al. There are more football injury prevention reviews than randomised controlled trials. Time for more RCT action! Br J Sports Med 2018:52:1477-8.

50 Lauersen JB, Bertelsen DM, Andersen LB. The effectiveness of exercise interventions to prevent sports injuries: a systematic review and meta-analysis of randomised controlled trials. Br J Sports Med 2014;48:871-7.

51 Grindstaff TL, Hammill RR, Tuzson AE, et al. Neuromuscular control training programs and noncontact anterior cruciate ligament injury rates in female athletes: a numbersneeded-to-treat analysis. J Athl Train 2006;41:450-6. 
52 Petersen J, Thorborg K, Nielsen MB, et al. Preventive effect of eccentric training on acute hamstring injuries in men's soccer: a cluster-randomized controlled trial. Am J Sports Med 2011;39:2296-303.

53 Herrero H, Salinero JJ, Del Coso J. Injuries among Spanish male amateur soccer players: a retrospective population study. Am J Sports Med 2014;42:78-85.

54 Delecroix B, McCall A, Dawson B, et al. Workload and non-contact injury incidence in elite football players competing in European leagues. Eur J Sport Sci 2018;18:1280-7.

55 Ardern CL, Taylor NF, Feller JA, et al. Fifty-five per cent return to competitive sport following anterior cruciate ligament reconstruction surgery: an updated systematic review and meta-analysis including aspects of physical functioning and contextual factors. Br J Sports Med 2014;48:1543-52.

56 Bangsbo J, Junge A, Dvorak J, et al. Executive summary: Football for health prevention and treatment of non-communicable diseases across the lifespan through football. Scand J Med Sci Sports 2014;24(Suppl 1):147-50.

57 Bangsbo J, Hansen PR, Dvorak J, et al. Recreational football for disease prevention and treatment in untrained men: a narrative review examining cardiovascular health, lipid profile, body composition, muscle strength and functional capacity. Br J Sports Med 2015;49:568-76.

58 Green B, Bourne MN, van Dyk N, et al. Recalibrating the risk of hamstring strain injury (HSI): a 2020 systematic review and meta-analysis of risk factors for index and recurrent hamstring strain injury in sport. Br J Sports Med 2020;54:1081-8.

59 Steffen K, Meeuwisse WH, Romiti M, et al. Evaluation of how different implementation strategies of an injury prevention programme (FIFA 11+) impact team adherence and injury risk in Canadian female youth football players: a clusterrandomised trial. Br J Sports Med 2013;47:480-7.

60 van der Horst N, Hoef Svande, Otterloo Pvan, et al. Effective but not adhered to: how can we improve adherence to evidence-based hamstring injury prevention in amateur football? Clin J Sport Med 2021;31:42-8.

61 McCall A, Dupont G, Ekstrand J. Injury prevention strategies, coach compliance and player adherence of 33 of the UEFA elite Club injury study teams: a survey of teams' head medical officers. Br J Sports Med 2016;50:725-30. 